\title{
DESENVOLVENDO UM PROCESSO ENSINO-APRENDIZAGEM: PRESSUPOSTOS E MÉTODOS DE ENSINO DA DISCIPLINA ENFERMAGEM PREVENTIVA E COMUNITÁRIA DO CURSO DE GRADUAÇÃO EM ENFERMAGEM*
}

\author{
Rosa Maria Godoy Serpa da Fonseca** \\ Maria Rila Bertolozzi** \\ Anna Maria Chiesa ** \\ Rosangela Maria Greco** \\ Emiko Yoshikawa Egry** \\ Maria Amélia Campos Oliveira**
}

FONSECA, R.M.G.S. da; BERTOLOZZI, M.R.; CHIESA, A.M.; GRECO, R.M.; EGRY, E.Y.; OLIVEIRA, M.A.C. Desenvolvendo um processo ensino-aprendizagem: pressupostos e métodos de ensino da disciplina enfermagem preventiva e comunitária do curso de graduaçăo em enfermagem. Rev. Esc. Enf. USP, v. 26, n. 3, p. - - , dez., 1992.

$O$ trabalho relata um processo ensino-aprendizagem guiado pelos pressupostos de dinamicidade, historicidade, participação e horizonte. Esse processo tem sido desenvolvido pela Disciplina Enfermagem Preventiva e Comunitaria da Escola de Enfermagem da Universidade de Säo Paulo. São descritos os objetivos, métodos e estratégias de condução do processo ensino-aprendizagem. Tal processo articula-se a Projeto de Integraşdo Docente-Assistencial que envolve a Escola de Enfermagem e a Prefeitura Municipal de São Paulo. Trata-se de uma experiência que se tem revelado valiosa tanto para os professores como para os alınos da disciplina e que tem permitido uma maior aproximaşăo com os trabalhadores das Unidades Básicas de Saúde.

UNITERMOS: Processo ensino-aprendizagem. Enfermagem Preventiva e Comunitaria.

\section{Introduçáo}

Desde o final da década de 70, quando a Habilitação em Enfermagem em Saúde Pública deixou de ser oferecida pela Escola de Enfermagem da Universidade de São Paulo, os conteúdos anteriormente ministrados pelas disciplinas Saúde Pública I e II, em nível de graduação, e parte do conteúdo contemplado pelas disciplinas Saúde Pública III e IV, em nivel de habilitaçăo, foram rearranjados para compor as duas disciplinas do Curso de Graduaçăo na atual grade cur-

- Trabalho apresentado como tema livre sob a forma de poster no $43^{\circ}$ Congresso Brasileiro de Enfermagem. Curitiba (PR), 11 a 16 de outubro de 1991.

* Enfermeira. Docentes do Departamento de Enfermagem em Saude Coletiva da Escola de Enfermagem da Universidade de Såo Paulo. 
ricular, ou seja Saúde da Comunidade (SC) e Enfermagem Preventiva e Comunitária (EPC).

Naquela época, baseado em pressupostos funcionalistas, o ensino destas disciplinas, pautava-se na visão que, ente outras coisas, a relação educador-educando devia ter um sentido unidirecional, do $1 \%$ para o $2^{\circ}$, considerando respectivamente, uns como fonte inesgotável de saber e outros, como meros depositários de conhecimentos técnicos normatizados. Esta visão, por sua vez, articulava-se à visão hegemónica da sociedade brasileira que, na época, valorizava a normatividade técnico-científica e política como sustentáculos da busca do desenvolvimento social através do "milagre económico". A derrocada desse sistema de idéias deu origem à escalada inevitável para a crise política que culminou na queda da ditadura militar de então. Neste processo, houve intensificação gradativa da participação de grupos organizados da população em praticamente todos os setores sociais, como pode ser percebido de vários movimentos reivindicatórios por melhores salários e condições de trabalho, inclusive na Universidade de São Paulo. $O$ engajamento nesses movimentos respondia a uma série de questionamentos que incluiam temas que se fundamentavam nas inquietaçőes dos docentes, inclusive naquelas relativas ao processo ensino-aprendizagem.

Especificamente na Escola de Enfermagem da Universidade de São Paulo houve a criação do Grupo de Trabalho sobre Currículo, onde alguns docentes, incluindo vários que ministravam as disciplinas $\mathrm{EPC}$ e $\mathrm{SC}$, iniciaram um processo de reflexão para a transformação do currículo vigente.

Nos anos que se seguiram e no prosseguimento das reflexões e da própria produção do trabalho docente, incluindo teses, investigações, etc., várias modificações foram feitas, tanto no conteúdo programático, como na forma de ensinar aquelas disciplinas anteriormente referidas.

Há dois anos, fruto deste intenso processo, teve início a aplicação de um método para o desenvolvimento do processo ensino-aprendizagem na disciplina EPC, fundamentalmente diferente do método anterior e considerando o aluno sujeito ativo do seu proprio desenvolvimento profissional.

Este trabalho tem como objetivo relatar a experiência vivenciada na aplicação deste método.

\section{1 - Considerações gerais sobre o conteúdo programático da disciplina EPC}

A disciplina EPC é ministrada no 70 semestre do curso de Graduação em Enfermagem. A carga horária de 270 horas é desenvolvida em 8 semanas, período integral, distribuídas entre ensino teórico e teórico-prático. Este é realizado em Unidades Básicas de Saúde da Administração Regional de Saúde - 8 (Pirituba-Perus) do Município de São Paulo, onde hă 3 anos se desenvolve um Projeto de Integração Docente Assistencial (PIDA), envolvendo a Escola de Enfermagem da USP e aquele município.

Os pressuspostos que norteiam este PIDA são os mesmos que norteiam o ensino de EPC, e são buscados no referencial teórico-metodológico adotado pela 
maioria do grupo de docentes da disciplina, que é o do materialismo histórico e dialético. São os seguintes(1):

- Dinamicidade: que significa que toda realidade social está em contínua transformação no tempo e no espaço. Da mesma forma, o processo ensino-aprendizagem é dinâmico e o seu desenvolvimento se dá segundo as 3 leis fundamentais da dialética: unidade e luta dos contrários; lei da transiçăo da mudança quantitativa para a qualitativa e a lei da negação da negação.(2)

- Historicidade: advém do entendimento de que a procura da causa final é a grande força motriz de todos os acontecimentos históricos importantes e deve ser buscada no desenvolvimento economico da sociedade, nas transformaçóes dos modos de produção e de troca, na conseqüente divisáo da sociedade em classes distintas e na luta entre essas classes. Assim, o processo ensino-aprendizagem tem raízes historicas que devem ser buscadas e apreendidas para a sua transformação.

- Participação: refere-se ao processo de manifestação das vontades pessoais no contexto do grupo, para que estas, sofrendo a ampliação que lhes impõe as contraposições das vontades alheias, possam compreender as articulaçōes entre as diferentes dimensóes do objeto fenomênico e, em conjunto, possam construir alternativas de equacionamento das questóes dentro das proposições grupais.

- Horizonte: "ć a qualidade nova, posto que estruturalmente diferente da anterior, projetada pela coletividade num processo de participação consideradas a dinamicidade e a historicidade dos processos sociais. Este horizonte, nåo sendo um objetivo ou meta é re-situado e re-dimensionado no decorrer do caminho para o seu aproximar. Em sociedades como a nossa há diferenças qualitativas dos horizontes de acordo com a classe social que o grupo social está inserido." (1)

Para que o processo ensino-aprendizagem possa ser desenvolvido deve-se aproximar da forma fenoménica do mundo material, ou seja da realidade objetiva, desdobrando-a em 3 dimensōes:

"...a dimensão estrutural, que é formada pelos processos de desenvolvimento da capacidade produtiva e do desenvolvimento das relaçōes de produção, da formação económica e social e das formas político-ideológicas derivadas; a dimensão particular, que é formada pelos processos de reprodução social, perfis epidemiológicos de classe - integrados pelo perfil reprodutivo de classe e perfil saúde-doença e formas especiais de prática e ideologia em saúde; e a dimensão singular, formada pelos processos que, em última instância, levam a adoecer e a morrer ou, ao contrário, a desenvolver o nexo biopsíquico dado pelo seu "funcionamento", consumo-trabalho individual e pelas formas de participação individual de organização e consciência" (3). 
Os objetivos da disciplina são os que seguem:

1. compreender a determinação social do processo saúde-doença;

2. analisar criticamente a atual estrutura do Sistema Nacional de Saúde;

3. reconhecer e analisar a problemática de saúde de uma dada região, priorizando as áreas programáticas, tendo em vista a inserção da clientela em diferentes classes sociais;

4. participar no planejamento, execução e avaliação dos programas locais de saúde, desenvolvendo um trabalho em equipe e colaborando nas transformaçóes desses programas, de acordo com as especificidades locais;

5. prestar assistência direta de enfermagem ao cliente nas áreas programáticas, desenvolvendo habilidades nas seguintes atividades: consulta de enfermagem, visita domiciliária, investigação epidemiológica, vacinação e ações de pronto atendimento;

6. prestar assistência direta de enfermagem a grupos da comunidade, em consonância com os programas, desenvolvendo habilidades em planejar, executar e avaliar trabalhos com grupos informativos ou participativos;

7. prestar assistência direta de enfermagem à familia, em consonância com os programas, desenvolvendo habilidades em planejar, executar e avaliar ações de enfermagem no domicílio e,

8. compreender o conceito de comunidade, de desenvolvimento de comunidade e o papel do profissional enfermeiro junto à comunidade.

O conteúdo programático da disciplina envolve:

1. A determinação social do processo saúde-doença;

2. A política de saúde no Brasil: evolução histórica e atual do Sistema Nacional de Saúde. Programas de Assistência à Saúde nos níveis central, estadual e local;

3. Referenciais de interpretação da intervenção no processo saúde-doença. Método de assistência de enfermagem em Saúde Coletiva no enfoque individual, familial e grupal. Desenvolvimento de comunidade e participação popular.

4. Assistência de enfermagem nos diversos programas e sub-programas de saúde: da mulher, da criança, do adulto, de vigilância epidemiológica e imunização. 
A sistematização do processo ensino-aprendizagem segue as etapas propostas por QUEIROZ e EGRY(3). Apesar de serem apresentadas de modo sequencial, guardam entre si uma relação de interpenetrabilidade. Cabe esclarecer que este método inicialmente foi preconizado para a assistência, todavia, atualmente tem sido aplicado tanto nesse âmbito quanto em outros relativos ao ensino-aprendizagem, à investigação, etc. No desenvolvimento da disciplina EPC, esta pluralidade e simultaneidade de aplicaçðes algumas vezes pode ser de difícil compreensão para o aluno, tornando-se necessário, por parte dos docentes, o aclaramento dos processos em curso.

\section{Primeira etapa: captação da realidade objetiva}

Consiste em conhecer a realidade objetiva nas três dimensões.

Esta etapa compreende a captação da realidade de ensino-aprendizagem do aluno, com a deteç̧ão de vazios de conhecimento em relação a assistência a ser prestada. Ao mesmo tempo, o aluno capta a realidade assistencial da Unidade Básica de Saúde (UBS), onde é desenvolvido o ensino teórico-prático. Num primeiro momento são revistos os conhecimentos técnicos relativos à assisténcia através dos programas de saúde da mulher, da criança e do sub-programa de imunização. Instrumentalizados por esses conhecimentos, os alunos vão às UBSs munidos de um roteiro e procedem à captação da realidade objetiva, não so através da observação, como também executando algumas atividades programáticas.

\section{Segunda etapa: interpretação da realidade objetiva}

Consiste na explicitação das contradições existentes, tanto no processo ensino-aprendizagem vivenciado pelos alunos, como na assistência prestada pelas UBSs.

Esta etapa é realizada em sala de aula, através de um processo reflexivo, onde participam alunos, docentes e profissionais de campo.

Terceira etapa: construção do projeto de intervenção na realidade objetiva

O projeto de intervenção no processo ensino-aprendizagem refere-se ao próprio conteúdo específico de enfermagem em Saúde Coletiva da disciplina EPC, ou seja, constitui o embasamento da prática de assistência no âmbito da Saúde Coletiva. O conteúdo programático sim é elaborado pelos docentes, sendo que no decorrer do processo poderá sofrer modificações substanciais, pois novos temas da realidade objetiva serão expostos, ou seja, captados e interpretados. Por conseguinte, esses temas são continuamente re-elaborados e re-situados permitindo uma maior aderência às necessidades dos alunos as quais estejam articulados aos processos mais gerais da sociedade(1). 
Nesta etapa são colocados em execução as proposições perfiladas no item anterior, ou seja, são desenvolvidos os temas de estudo, procurando-se buscar na relação teórico-prática a superação das dificuldades dos alunos. São utilizadas várias estratégias para isto, as quais, em geral, propiciam aos mesmos tornarem-se sujeitos do seu proprio aprendizado. Assim, são utlizadas técnicas como as de dramatização e de trabalhos com sucata, entre outras. No âmbito da prática são executadas todas as atividades que fazem parte do leque daquelas desenvolvidas pelas UBSs (atendimento de enfermagem, vacinação, investigação epidemiológica, ações de pronto-atendimento, etc.) e outras que, apesar de não serem rotineiramente executadas pelas Unidades Básicas, sāo reputadas como de valor inigualável, tanto para o ensino como para a assistência (consulta de enfermagem e visitas domiciliárias).

Além destas, são utilizadas estratégias convencionais como preleções, seminários, discussão em grupo, leituras programadas, estudos dirigidos, visitas a instituições e demonstraçōes de técnicas e procedimentos.

Essas estratégias são escolhidas sempre tendo-se em mente as possibilidades de superação das dificuldades dos alunos em termos do conteúdo a ser apreendido e a vulnerabilidade espacial e temporal, ou seja, a oportunidade ou época em que poderá haver a superação das contradições expostas(1).

\section{Quinta etapa: reinteração da realidade objetiva}

Nesta última etapa há releitura da realidade objetiva de ensino-aprendizagem dos alunos através de vários momentos de avaliação que percorrem todo o processo, a saber:

1. avaliação do conteúdo teórico sob a forma de uma prova escrita, com questões dissertativas, realizada antes do início do estágio. Nesse momento verificam-se quais são as lacunas de conhecimento do aluno, visando surpí-las antes que iniciem as atividades de campo.

2. iniciado o estágio de campo, é feita uma avaliação diária do desempenho dos alunos, onde é verificado o aproveitamento individual de cada um e são dadas as orientações específicas.

3. decorrida a primeira metade do estágio de campo, é feita uma avaliação com o uso de uma técnica participativa, quando é solicitado a cada aluno que reconstrua e represente o caminho percorrido até então, retomando-se os objetivos da disciplina.

4. ao final do curso é feita uma nova prova dissertativa cujas questóes remetem aos alunos às situações vivenciadas no estágio de campo, para verificar qual a articulação que estes fazem entre os conhecimentos teóricos e aqueles adquiridos através da sua prática concreta no campo. 
5. os grupos de alunos de cada um dos campos de estágio apresentam também um relatório das intervenções que realizaram sobre os problemas detectados no campo.

\section{Considerações finais}

O processo percorrido nesses últimos anos têm trazido inegáveis avanços e satisfações para o desenvolvimento pessoal e profissional de alunos e professores, no entanto, não sem ser às custas de muitos questionamentos e percalços, especialmente no decorrer do mesmo. Por tratar-se de um método singular dentro da Escola de Enfermagem da USP, especialmente porque se baseia num referencial teórico-metodológico que não é hegemonico na Instituição e por ser aplicado no penúltimo semestre do Curso de Graduação, os alunos enfrentam inúmeras dificuldades até entenderem a sua totalidade, tanto no que se refere aos pressupostos, como às etapas do método.

Estas incompreensões algumas vezes chegam a por em risco a relação de confiança que deve se estabelecer entre educador e educando para que o processo ensino-aprendizagem seja eminentemente emancipatório.

Além dessas dificuldades operacionais há a questão do currículo da EEUSP, pois da maneira como se encontra estruturado, não contempla níveis de complexidade crescente na assistência de enfermagem, nem tampouco parte do concreto para o abstrato ou integra os conhecimentos de disciplinas como sociologia, psicologia, imunologia, estatística, dificultando ao aluno a compreensão da forma de assistir preconizada pela disciplina EPC.

A maior dificuldade, no entanto, reside em compatibilizar o vasto conteúdo relatico à Saúde Coletiva com as $\mathbf{2 7 0}$ horas que cabem à disciplina.

A despeito de tudo o que foi dito anteriormente, os ganhos obtidos na aplicação deste processo ultrapassam as fronteiras do crescimento profissional, atingindo um repensar sobre a propria vida dos envolvidos, como resumem muito bem, algumas falas de alunas que o experimentaram:

- "Hoje percebo que, na verdade, a assistência de Enfermagem que se encontra nessa disciplina não está justamente voltada para a prevenção da doença (pelo menos não é só isso). O que se faz é Saúde Coletiva, onde a assistência está voltada para o indivíduo como um todo, dentro do "seu coletivo", inserido num contexto maior que todo um sistema socio-economico determinante de seu papel, de suas condições de vida, enfim, do seu processo saúde-doença."

- "Pensei que sabia o que era pobreza, mas na verdade não sabia. Eu tive nesta disciplina uma lição de vida e não um aprendizado de EPC. Gostei, gostei muito!".

- "A dialética acaba com a cabeça da gente mas, depois que a gente entende, fica muito legal!" 
FONSECA, R.M.G.S. da; BERTOI.O7ZI, M.R.; CHIESA, A.M.; GRECO, R.M.; EGRY, E.Y.; OLIVEIRA, M.A.C. Developing a teaching-learning process: presuppositions and methods of teaching improved by Community and Preventive Nursing Discipline of the School of Nursing of São Paulo University. Rev. Esc. Enf. USP, v. 26, n. 3, p. - - , dec., 1992.

This paper describes the development of a teaching-learning process (TLP) guided by presuppositions such as: historicity, participation and horizon. This process has been developed by the Community and Preventive Nursing Discipline of the School of Nursing of Säo Paulo University, and its objectives, methods and strategies are described here. Its is articulated to the Assistance-Teaching Integration Project involving the School of Nursing and Säo Paulo Mayorality. This process has been a valuable experience for both teachers and students, and it has also enabled a real approach with the Health Unit personnel.

UNITERMS: Teaching-learning process. Commnunity health nursing.

\section{REFERÊNCIAS BILIOGRÁFICAS}

1. EGRY, E.Y. Sistematização da assistencia de enfermagem em saúde coletiva orientada pelo materialismo histórico e dialético: em busca do horizonte de unicidade entre o saber e o fazer. In: SEMANA WANDA DE AGUIAR HORTA, 3. São Paulo, 1990. Anais. São Paulo, Escola de Enfermagem da Universidade de São Paulo, 1990, p.97-110.

2. FONSECA, R.M.G.S. da. Mulher, reprodução biologica e classe social: a compreensão do nexo coesivo । através do estudo dialético do perfil reprodutivo biológico de mulheres atendidas em Unidades Básicas de Saúde. São Paulo, 1990, 336p. Tese (Doutorado) - Escola de Enfermagem, Universidade de São Paulo.

3. QUEIROZ, V.M.; EGRY, E.Y. Bases metodológicas para a assistência de enfermagem em saúde coletiva fundamentadas no materialismo histórico e dialético. Apresentado no $39^{\circ}$ Congresso Brasileiro de Enfermagem, Salvador, 1987/. 